\title{
Royal jelly lipophilic fraction induces antiproliferative effects on SH-SY5Y human neuroblastoma cells
}

\author{
ANGELO GISMONDI, ELEONORA TRIONFERA, LORENA CANUTI, \\ GABRIELE DI MARCO and ANTONELLA CANINI
}

Department of Biology, University of Rome 'Tor Vergata', I-00133 Rome, Italy

Received February 7, 2017; Accepted June 26, 2017

DOI: 10.3892/or.2017.5851

\begin{abstract}
Royal jelly (RJ) is one the most important bee product because it strongly influences the larval development in the hive, including the queen bee. In literature, RJ is known for its antioxidant, immunoregulatory, antifungal, antibiotical, ery thropoietic, hy poglycemic, anticholesteremic, antithyroidic, anti-osteoporotic and estrogenic properties. However, it is surprising how rare the scientific evidence about RJ antineoplastic capacity are. That being said, we investigated, for the first time, the in vitro bioactivity of six different RJs on the growth of three different mammalian cell lines: immortalized murine myoblasts (C2C12), human prostate cancer (PC3) and human neuroblastoma (SH-SY5Y). These studies were performed treating the cells with the only lipophilic, or hydrophilic, fraction of the RJs, a scientific approach never performed before. Moreover, chemical and protein profiles of all RJs were finely characterized, in qualitative and quantitative terms, by GC-MS and 1D-SDSPAGE, respectively, in order to give a complete framework to the research. Despite the deep differences we found in the composition of each sample, unexpectedly, RJs showed comparable or very similar biological effects. In particular, our attention was captured by the extraordinary antiproliferative activity of the lipophilic extract of all RJs against SH-SY5Y cells, suggesting a potential medical application of this bee product to prevent the onset and slow down the growth of human neuroblastoma.
\end{abstract}

\section{Introduction}

Royal jelly (RJ) is an animal secretion produced by hypopharyngeal and mandibular glands of worker honeybees

Correspondence to: Professor Antonella Canini, Department of Biology, University of Rome 'Tor Vergata', Via della Ricerca Scientifica 1, I-00133 Rome, Italy

E-mail: canini@uniroma2.it

Key words: honeybees, PC3 cells, C2C12 cells, SH-SY5Y cells, gas-chromatography, protein profile, lipophilic fraction, hydrophilic portion
(Apis mellifera L.) that are from 5- to 14-day-old. It represents the principal food source for all the larvae in the hive, until the third day of age, and for the queen bee, for the whole life (1). As the queen honeybee is the only fertile organism in the hive, its life expectancies are the highest of the colony and its morphological traits are unique and very peculiar (i.e. big dimensions, reduction of faringeal and wax glands, absence of pollen pocket, growth of pheromonal glands and gonads), it appears clear that a RJ-based diet can strongly influence honeybee's development and destiny, acting on gene expression and metabolism (2).

RJ chemical composition varies according to honeybee species, physiological state of the colony, environmental conditions and production period. Generally, it contains water (50-60\%), nitrogen compounds (18\%), sugars $(15 \%)$, lipids (3-6\%), mineral salts $(1.5 \%)$ and traces of vitamins (3). Among nitrogen compounds, free essential amino acids, several enzymes (i.e. glucose oxidases, phosphatases and cholinesterases) and five honeybee typical proteins (major royal jelly proteins, MRJP) were detected (4-7). Fructose is the main carbohydrate $(50 \%)$, followed by glucose (33-43\%), sucrose (6\%) and other minor saccharides (8). Finally, although in low concentration, the lipid profile may be considered a fingerprint for RJ. This class of molecules includes short-chain (8C-10C) fatty acids, such as trans10-hydroxy-2-decenoic acid (10-HDA), non-polar lipids, sterols, including cholesterol, and a non-saponifiable fraction of hydrocarbons (9-11).

Various studies document that RJ possesses many biological properties on murine and human cell systems. In particular, it was demonstrated to have antioxidant $(12,13)$, anti-inflammatory (14), anticholesteremic (15), hypoglycemic, erythropoietic (16), antithyroidic (17), immunostimulatory $(18,19)$, anti-osteoporotic (20), antifungal and antibiotic properties, especially against Escherichia coli, Salmonella ssp., Proteus ssp., Bacillus subtilis and Staphylococcus aureus (21,22). In addition, Taniguchi et al (23) and Shirzad et al (24) demonstrated that RJ had an important role in control and regression of murine fibrosarcoma tumors. Of note, Tamura et al (25) even suggested that RJ could exert a significant antiproliferative activity against slow-growing cancers but not towards fast-growing ones. However, it is surprising and unexpected to note the scarce scientific evidence reported on $\mathrm{RJ}$ antineoplastic power. 
To extend our knowledge on RJ medical potentialities, we investigated the in vitro bioactivity of six different RJs on the growth of three mammalian cell lines: immortalized murine myoblasts (C2C12), human prostate cancer (PC3) and human neuroblastoma (SH-SY5Y). In fact, no data are provided in literature on the effect of this matrix on these specific cells. Moreover, the originality of our study also consisted in performing separate analyses on the lipophilic and hydrophilic portions of the RJs, an approach never performed before, in order to better discriminate the biological role of both these fractions. Finally, to establish a complete framework, biochemical and protein profiles of the RJs were deeply characterized by gas chromatography-mass spectrometry (GC-MS) and one-dimensional sodium dodecyl sulfate-polyacrylamide gel electrophoresis (1D-SDS-PAGE), respectively.

\section{Materials and methods}

Sample material. Six different RJs were used in the current study. Three of them (P1, P2 and P3) were bought directly from local producers of RJ, while the others (G1, G2 and G3) were purchased from National Pharmaceutical Societies. The Honey Research Center of the University of Rome 'Tor Vergata' certified freshness, authenticity and quality (i.e. absence of pesticide and antibiotic contamination) of the samples. RJs were stored at $4^{\circ} \mathrm{C}$ until their analysis.

GC-MS analysis. For GC-MS study, RJs were separated in two fractions, according to their lipophilicity, as described in Isidorov et al (26). Briefly, $500 \mathrm{mg}$ of RJ were resuspended in $10 \mathrm{ml}$ of diethyl ether and constantly mixed for $15 \mathrm{~min}$ at room temperature. Then, after centrifugation for $5 \mathrm{~min}$ at maximum speed $(13.000 \mathrm{rpm})$ at $4^{\circ} \mathrm{C}$, the supernatant was recovered, filtered by a Millipore $0.45 \mu \mathrm{m}$ sieve and conserved at $4^{\circ} \mathrm{C}$. On the other hand, the pellet, containing more polar and less lipophilic compounds, was subjected to methanol extraction, following the same identical steps previously performed in the procedure with diethyl ether. Finally, both samples were completely dried out under nitrogen flow and then resuspended with $500 \mu \mathrm{l}$ of diethyl ether or methanol, respectively. Each extract $(1 \mu \mathrm{l})$ was injected in a GC-MS instrument (QP2010 Shimadzu, Japan) and analyzed. The chromatographic separation was performed, in a DB-5 column $(30 \mathrm{~m} \times 0.25 \mathrm{~mm} \times 0.25 \mu \mathrm{l}$; Agilent Technologies, Santa Clara, CA, USA), setting the GC oven as follows: $50^{\circ} \mathrm{C}$ for $10 \mathrm{~min}, 150^{\circ} \mathrm{C}$ (reached at a rate of $5^{\circ} \mathrm{C} / \mathrm{min}$ ) for $10 \mathrm{~min}, 280^{\circ} \mathrm{C}$ (reached at a rate of $1^{\circ} \mathrm{C} / \mathrm{min}$ ) for $35 \mathrm{~min}$. Helium was used as carrier gas at a constant flow of $2.1 \mathrm{ml} / \mathrm{min}$. MS conditions and details about the identification of the molecules was the same of those reported in Gismondi et al (27). The amount of each compound was expressed as percentage of its relative abundance in the RJ, as described in Giovannini et al (28).

Protein study. Lipophilic and hydrophilic protein portions of RJs were purified according to the procedure of Li et al (29) adequately modified. In brief, $200 \mu \mathrm{l}$ of $1 \mathrm{X}$ phosphatebuffered saline (PBS) were added to $100 \mathrm{mg}$ of RJ. The solution was vortexed for $5 \mathrm{~min}$, sonicated for further $5 \mathrm{~min}$ and centrifuged for $10 \mathrm{~min}$ at maximum speed at $4^{\circ} \mathrm{C}$. The supernatant, containing the hydrosoluble protein portion, was recovered, transferred into a new Eppendorf tube and stored at $4{ }^{\circ} \mathrm{C}$. On the contrary, the pellet was resuspended with $200 \mu \mathrm{l}$ of solubilization buffer (SB: $7 \mathrm{M}$ urea; $2 \mathrm{M}$ thiourea; 4\% 3-[(3-cholamido propyl)-dimethylammonio]1-propane sulfonate; $0.8 \%$ IPG-buffer pI 3-10 NL; $1 \%$ DTT) and subjected to the same previous passages. This second supernatant, including the liposoluble protein portion, was conserved at $4^{\circ} \mathrm{C}$, while the pellet was discarded. At this point, both the extracts were enriched with $22 \mu \mathrm{l}$ of $100 \%$ trichloroacetic acid and put on ice for $10 \mathrm{~min}$, in order to favour protein precipitation. Then, samples were centrifuged at $4^{\circ} \mathrm{C}$ for $10 \mathrm{~min}$ at maximum speed. While the supernatants were discarded, the protein pellets, resuspended with $100 \mu \mathrm{l}$ of $\mathrm{SB}$, were stored at $-20^{\circ} \mathrm{C}$ until their analysis. Protein quantitation was carried out according to Bradford (30) method, using a specific dye reagent (Quick Start Bradford, Bio-Rad Laboratories, Milan, Italy) and bovine serum albumin as standard (Sigma-Aldrich, Milan, Italy). Finally, protein samples were fractionated through 1D-SDS-PAGE (12\% concentrated) for $30 \mathrm{~min}$ at $80 \mathrm{~V}$ and further $60 \mathrm{~min}$ at $120 \mathrm{~V}$. Gels were stained with Coomassie blue (G-250) for $2 \mathrm{~h}$, destained three times for $30 \mathrm{~min}$ in methanol, acetic acid and water (2:3:5; v/v/v) and photographed by VersaDoc (Bio-Rad Laboratories) instrument associated to Quantity One software (Bio-Rad Laboratories).

Cell growth assay. Lipophilic and hydrophilic fractions of each RJ were purified as follows. RJ $(250 \mathrm{mg})$ were resuspended in $1 \mathrm{ml}$ of $1 \mathrm{X}$ PBS, vortexed for $30 \mathrm{~min}$ and centrifuged at maximum speed for $10 \mathrm{~min}$ at $4^{\circ} \mathrm{C}$. The supernatant, containing the hydrosoluble portion of $\mathrm{RJ}$, was transferred into a new Eppendorf tube, while the pellet was resuspended in $1 \mathrm{ml}$ of dimethyl sulfoxide (DMSO) and subjected to the same previous protocol, in order to obtain the liposoluble portion of RJ. Hence, the final pellet was discarded, while both the extracts were stored at $4^{\circ} \mathrm{C}$ until their application as cell treatment. Tumoral (PC3 and SH-SY5Y) or health $(\mathrm{C} 2 \mathrm{C} 12)$ mammalian cell lines were cultivated as widely reported in Gismondi et al (31). In particular, PC3 and C2C12 were propagated in D-MEM (Dulbecco's modified Eagle's medium), while SH-SY5Y in D-MEM/Ham's F12 (1:1). Cells were equally distributed in 24-well plates and treated, for 24 and $48 \mathrm{~h}$, with 1,3 or $5 \mu \mathrm{l}$ of hydrophilic or lipophilic RJ extract per $\mathrm{ml}$ of culture medium, which corresponded to the hydrosoluble or liposoluble molecules contained in 250, 750 and $1250 \mu \mathrm{g}$ of $\mathrm{RJ}$, respectively. Control cells (CNT) were treated with equal volumes of PBS 1X or DMSO for the same times. Cell growth was monitored using the MTT (3-(4,5-dimethylthiazol-2-yl)2,5-diphenyltetrazolium bromide) assay carried out exactly according to manufacturer's guidelines (Sigma-Aldrich). Results were expressed as percentage variation of the cell proliferation with respect to control (PBS or DMSO CNT), considered as unit (100\%).

Statistics. All data were expressed as mean \pm standard deviation (s.d.) of the relative results obtained in three independent replicates $(n=3)$. The significance of the analyses was measured by One-way ANOVA test, using PAST software; p-values $<0.05$ (vs. control) were considered significant. 
A
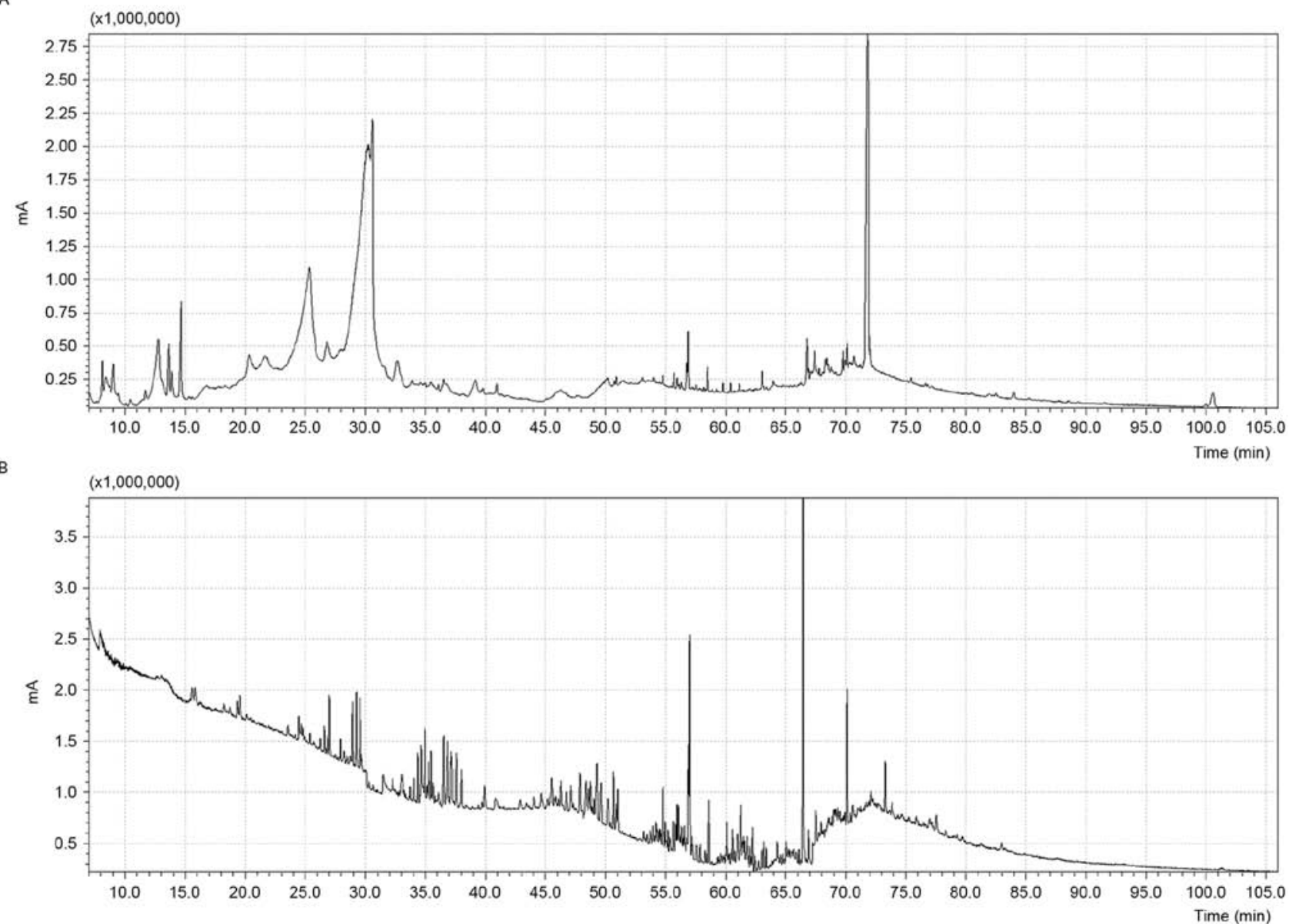

Figure 1. Gas-chromatographic profiles. Chromatograms reporting the chemical profiles of one representative RJ extracted both in diethyl ether (A) and in methanol (B) are shown. In the graphs, the $\mathrm{x}$-axis represents the retention time of the molecules in the column (minutes), while the y-axis is the detected total ion current (milliAmpere, $\mathrm{mA}$ ).

\section{Results}

GC-MS profiles of RJs. GC-MS analysis detected 276 molecules in the diethyl ether extracts of the RJs. On the contrary, the methanol extractions appeared to be richer than the previous ones, containing a total of 348 different compounds. In fact, as shown in Fig. 1, the GC profiles of the methanol extracts presented a higher number of peaks in comparison with the chromatograms obtained analyzing the diethyl ether extracts of the RJs.

The lists of molecules identified both in diethyl ether and in methanol extracts of each RJs are shown in Table I. In this table, the amount of each compound was reported as percentage of relative abundance (\% RA) in the RJ. In order to resume our results, all the molecules revealed into the diethyl ether extracts were grouped in four classes of frequency: class 1 , including compounds identified in all the RJs; class 2, containing molecules present, at least, in 4 RJs; class 3, presenting rare compounds detectable in 2 or $3 \mathrm{RJs}$; class 4 , clustering all the substances which could be found only in one RJ. According to this classification, in the diethyl ether samples, we detected 4 molecules for the class 1 (eicosane; dodecane 2,6,11-trimethyl; octacosyl trifluoroacetate; phenantrenemetil2-phenilcinnamato) and 13, 49 and 210 other compounds for the class 2, 3 and 4, respectively (Table I). Likewise, the chem- ical species identified in the methanol extracts were grouped in similar classes of frequency. In this case, no molecule could be included in class 1 , while 15,66 and 267 compounds were grouped in class 2, 3 and 4, respectively (Table I).

To better describe the mean composition of the RJs, we further classified all the molecules detected in the diethyl ether extracts in different molecular groups as follows: alkanes $(25.27 \%)$, acids (including fatty acids; $19.92 \%)$, aromatic derivatives (17.02\%), alcohols (15.94\%), alkenes $(7.60 \%)$, carbohydrates and sugary derivatives (1.81\%), quinolinic derivatives $(1.45 \%)$, oligopeptides and amino acids (1.08\%), coumarins $(0.72 \%)$ and others (i.e. aldehydes, ketones, nitrilic derivatives; $10.50 \%)$. In contrast, on the average, the methanol extracts of the RJs contained a high concentration of fatty acids (37.35\%) followed by alcohols $(13.21 \%)$, aromatic derivatives $(10.34 \%)$, alkanes $(5.45 \%)$, carbohydrates and sugary derivatives $(4.02 \%)$, oligopeptides and amino acids (4.02\%), alkenes $(3.44 \%)$, quinolinic derivatives $(2.01 \%)$, cholesterol derivatives $(0.6 \%)$ and others (i.e. aldehydes, ketones, nitrilic derivatives; $19.54 \%)$.

The diethyl ether extract of the P1 RJ revealed the highest level of 10-HDA (7.41\%) of the remaining ones. Moreover, only this sample presented the squalane $(1.93 \%)$, an ester of the leucin $(0.07 \%)$, a glycine dipeptide $(0.22 \%)$ and the decanedioic $(0.04 \%)$ and myristoleic $(0.03 \%)$ acids. P1 methanol extract 


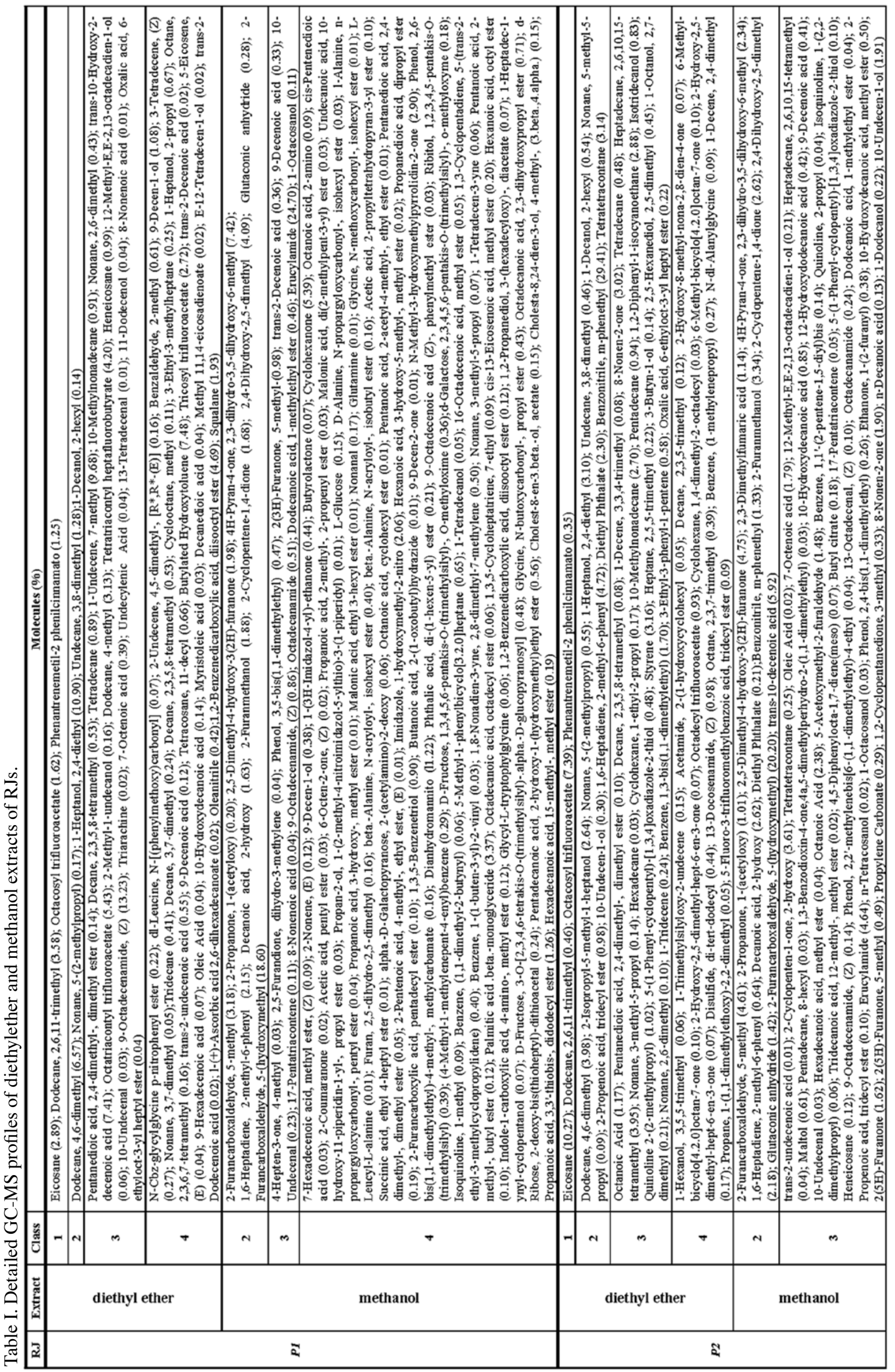




\begin{tabular}{|c|c|c|c|c|c|c|c|c|c|}
\hline 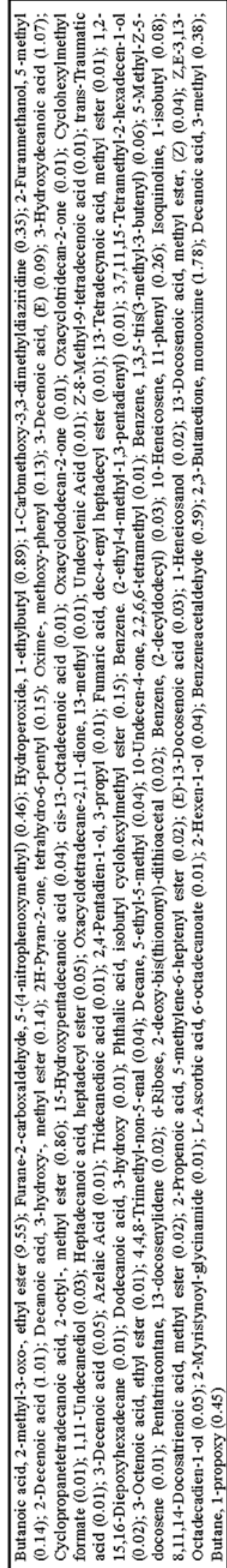 & 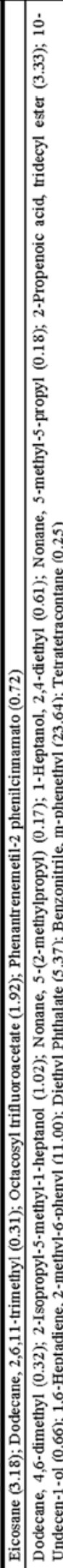 & & 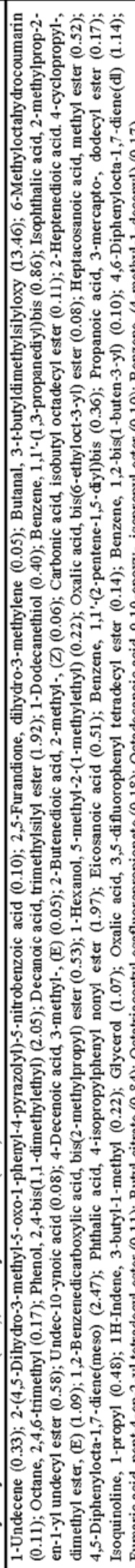 & 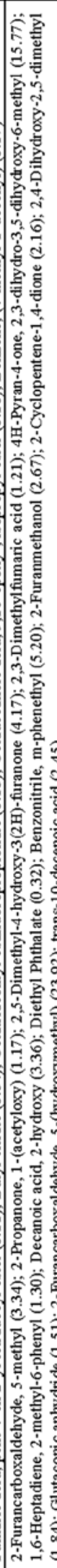 & 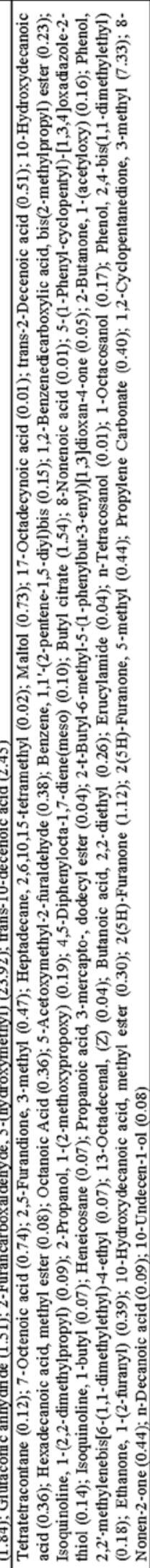 & 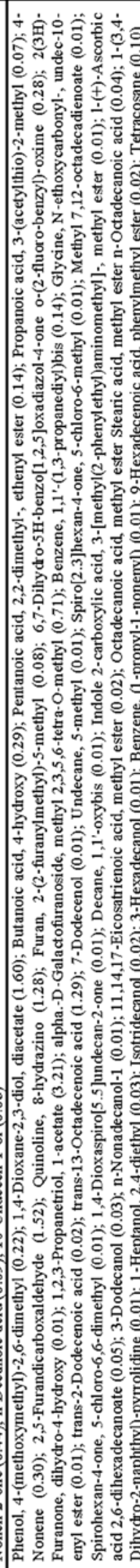 & 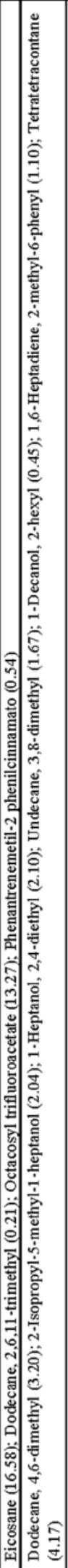 & 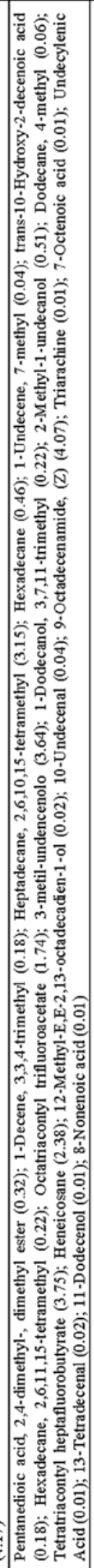 & 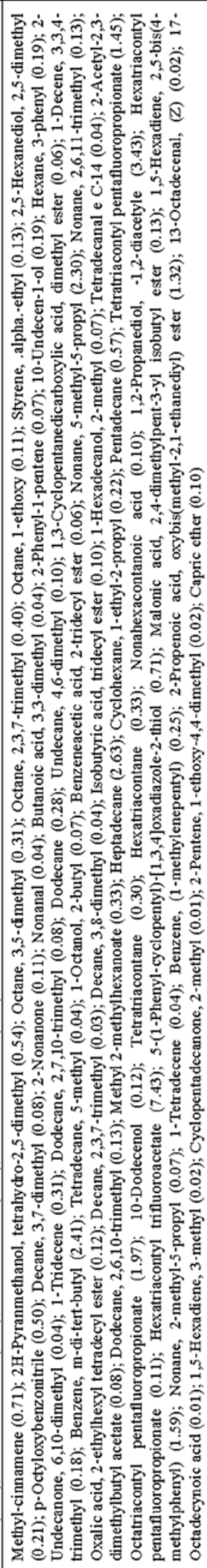 \\
\hline+ & $N$ & $m$ & + & $\mathrm{N}$ & $m$ & + & $N$ & $m$ & $\overrightarrow{+}$ \\
\hline & \multicolumn{3}{|c|}{ diethyl ether } & \multicolumn{3}{|c|}{ methanol } & \multicolumn{3}{|c|}{ diethyl ether } \\
\hline & \multicolumn{6}{|c|}{$\cong$} & & & 5 \\
\hline
\end{tabular}




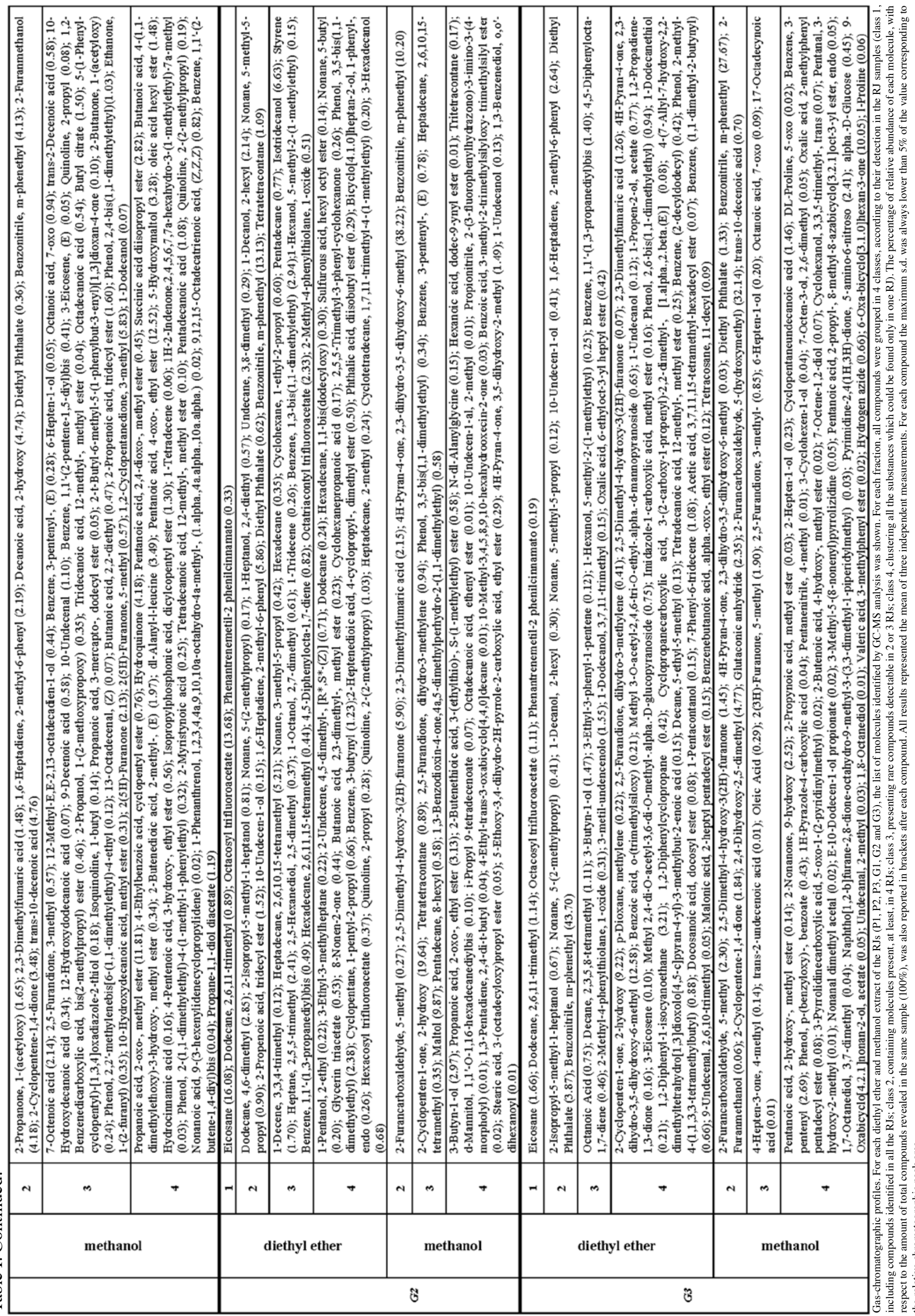



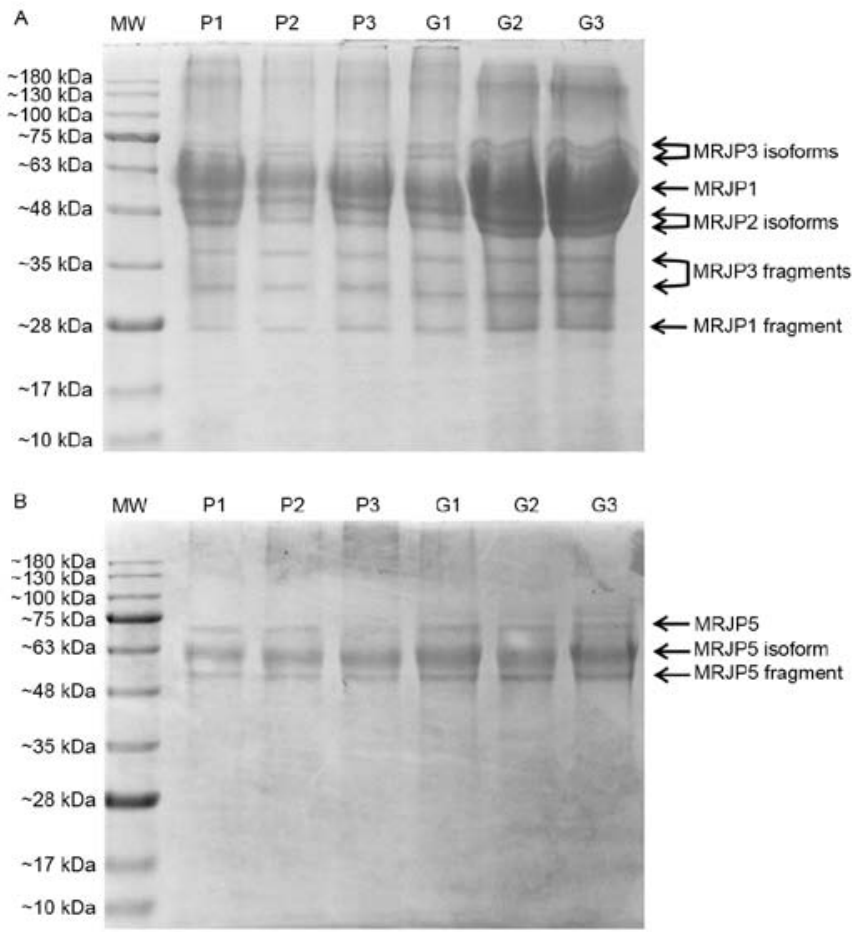

Figure 2. Protein detection. RJ hydrophilic (A) and lipophilic (B) proteins were separated on one-dimensional SDS PAGE and revealed by Coomassie blue staining. Representative gels of three independent replicates, with similar results, are shown. Molecular ladders (MW) were loaded into the gel, together with the RJ samples (P1, P2, P3, G1, G2 and G3), to determine the weight of each protein spot. On the right, the identity of each band was reported.

was characterized by high doses of 2-Furancarboxaldehyde, 5-(hydroxymethyl) (18.60\%) and Erucylamide (24.70\%). It was also the richest of the RJs in typical molecules (class 4), including 80 different peculiar compounds (see Table I).

P2 sample showed the greatest amounts of 2-Isopropyl5-methyl-1-heptanol (2.64\%), 8-Nonen-2-one (3.02\%) and Octanoic acid (1.17\%), with respect to all the other diethyl ether extracts. On the other hand, it was the least characteristic of the RJs, according to the low number (n. 19) of specific compounds (class 4) which typified it. The methanol extract of the P2 RJ was rich in 2-furancarboxaldehyde, 5-(hydroxymethyl) (20.20\%), 10-HDA (5.92\%), 2,5-dimethyl4-hydroxy-3(2H)-furanone $(4.75 \%)$, erucylamide $(4.64 \%)$ and 2-furancarboxaldehyde, 5-methyl (4.61\%). Among the substances unique in this sample we found an ester of the butanoic acid (9.55\%), the 2-decenoic acid (1.01\%), the 3 -Hydroxydecanoic acid (1.07\%) and traces of ribose and ascorbic acid.

P3 showed a diethyl ether extract which presented the highest concentration of 1,6-heptadiene, 2-methyl-6-phenyl (10.99\%) among all the other RJs. Moreover, it typically contained phthalic and butanal derivatives. The methanol preparation of this RJ was rich in 2-furancarboxaldehyde, 5-(hydroxymethyl) (23.92\%), 4H-pyran-4-one, 2,3-dihydro3,5-dihydroxy-6-methyl (15.77\%) and 1,2-cyclopentanedione, 3 -methyl $(7.33 \%)$. The same extract singularly included trans13-octadecenoic acid (1.29\%), quinoline, 8-hydrazino (1.28\%), ascorbic acid $(0.05 \%)$ a galactofuranoside derivative $(0.71 \%)$, a pentanoic acid ester $(0.14 \%)$ and a glycin $(0.01 \%)$ ester.
Table II. Protein quantitation.

\begin{tabular}{lcc}
\hline RJ & $\begin{array}{c}\text { Hydrosoluble protein } \\
\text { content }(\mu \mathrm{g} / \mathrm{mg})\end{array}$ & $\begin{array}{c}\text { Liposoluble protein } \\
\text { content }(\mu \mathrm{g} / \mathrm{mg})\end{array}$ \\
\hline P1 & $0.854 \pm 0.017$ & $0.262 \pm 0.005$ \\
P2 & $0.831 \pm 0.024$ & $0.396 \pm 0.007$ \\
P3 & $0.967 \pm 0.048$ & $0.207 \pm 0.006$ \\
G1 & $1.072 \pm 0.053$ & $0.313 \pm 0.009$ \\
G2 & $1.021 \pm 0.020$ & $0.545 \pm 0.010$ \\
G3 & $1.174 \pm 0.035$ & $0.525 \pm 0.026$ \\
\hline
\end{tabular}

Hydrosoluble and liposoluble protein content of each RJ (P1, P2, $\mathrm{P} 3, \mathrm{G} 1, \mathrm{G} 2$ and G3) was reported as $\mu \mathrm{g}$ per mg of sample. Data represent the mean \pm s.d. of the results obtained in three different measurements.

The GC profile of the G1 diethyl ether extract revealed the highest level of eicosane $(16.58 \%)$ and tetratetracontane (4.17\%). Sixty-two different molecules, such as methylcinnamene and capric ether, typically characterized this sample (class 4, Table I). The methanol extract of the G1 RJ presented the most elevated doses of decanoic acid, 2-hydroxy(4.74\%), 2-furanmethanol (4.18\%) and $2(5 \mathrm{H})$-furanone $(2.13 \%)$ with respect to the other RJs. Moreover, propanoic acid $(11.81 \%)$ and pentanoic acid $(12.52 \%)$ esters represented the most abundant specific markers of this same sample.

The diethyl ether extracts of the G2 and G3 RJs showed the higher concentration of octacosyl trifluoroacetate (13.68\%) and benzonitrile, m-phenethyl (43.70\%), respectively. In particular, G2 sample was typified by the presence of 3-butynyl-benzene, 3,5-bis(1,1-dimethylethyl)-phenol and 2-(2-methylpropyl)-quinoline, while G3 preparation was characterized by high doses of 2-Cyclopenten-1-one, 2-hydroxy- (9.22\%) and 4H-Pyran-4-one, 2,3-dihydro3,5-dihydroxy-6-methyl- (12.58\%). The G2 methanol extract revealed elevated amounts of $4 \mathrm{H}$-Pyran-4-one, 2,3-dihydro3,5-dihydroxy-6-methyl- (38.22\%), benzonitrile, m-phenethyl (10.20\%) and 2-cyclopenten-1-one, 2-hydroxy (19.64\%). The same extract singularly included 3-butyn-1-ol (2.97\%), N-dlalanylglycine $(0.15 \%)$, Stearic acid ester $(0.05 \%)$ and a mannitol derivative $(0.1 \%)$. On the other hand, the methanol extract of the G3 RJ was rich of benzonitrile, m-phenethyl (27.67\%), 2-furancarboxaldehyde, 5-(hydroxymethyl) (32.14\%) and glutaconic anhydride (2.35\%). Finally, 6-oxa-bicyclo-hexan3-one, 5-amino-6-nitroso-pyrimidine-2,4(1H,3H)-dione, 3-pentenyl-benzene, 9-hydroxy-2-nonanone and cyclopentaneundecanoic acid were the compounds that could be identified only in G3 sample.

Protein quantitation and analysis. Hydrosoluble and liposoluble protein portions of the RJs were purified as reported in Materials and methods and then quantified by Bradford method (30). As shown in Table II, all the RJs contained a greater amount of hydrosoluble proteins than liposoluble ones. In particular, the highest and the lowest contents of hydrophilic proteins were detected in G3 $(1.174 \mu \mathrm{g} / \mathrm{mg})$ and 

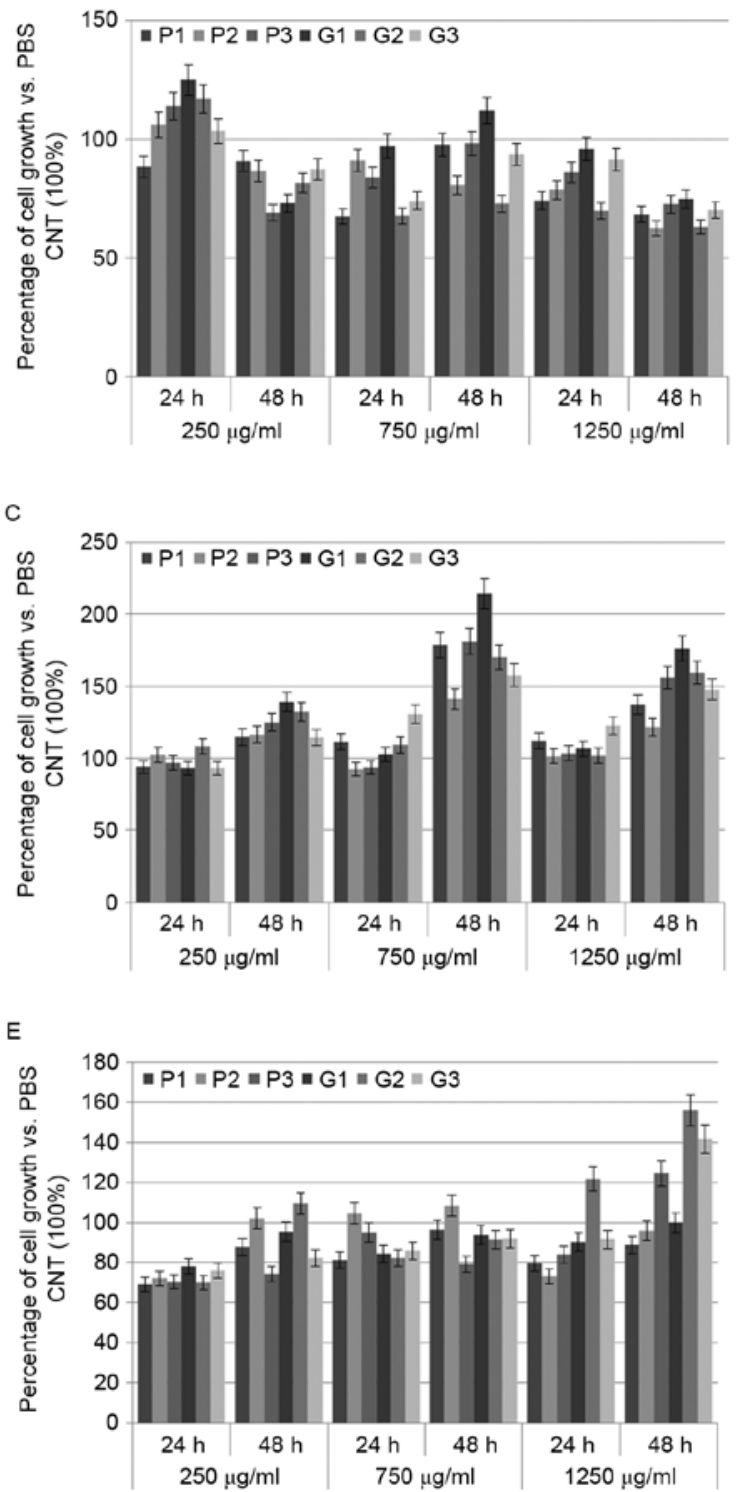

B

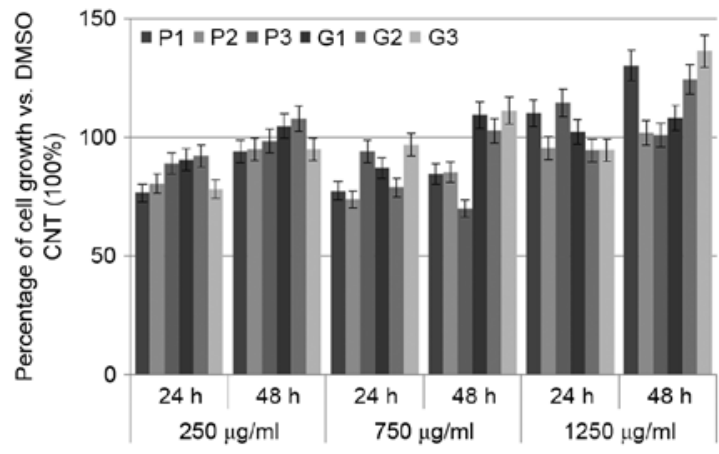

D

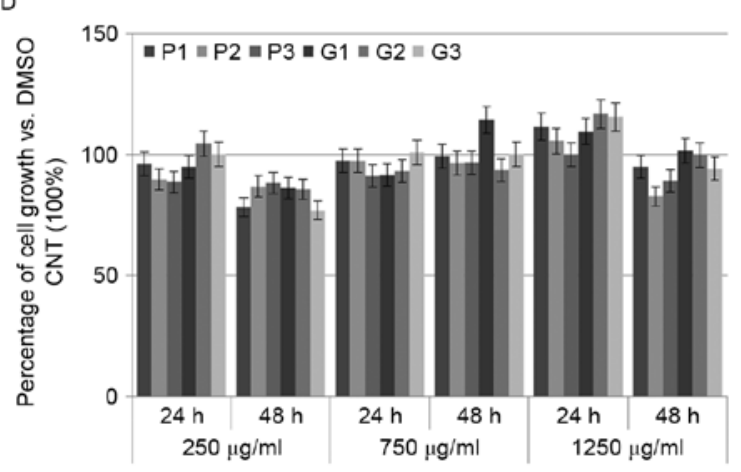

F

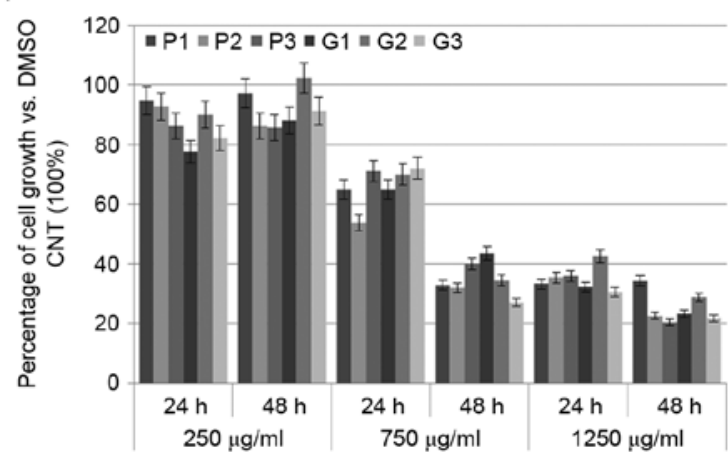

Figure 3. RJ bioactivity on mammalian cells. The graphs represent the results obtained by MMT assay performed on C2C12 (A and B), PC3 (C and D) and SH-SY5Y (E and F) cells after treatment, for 24 and 48 h, with hydrophilic (A, C and E) or lipophilic (B, D and F) extract of RJs (P1, P2, P3, G1, G2 and G3) at different concentrations (250, 750 and $1250 \mu \mathrm{g}$ per $\mathrm{ml}$ of culture medium). Results are reported as percentage of cell growth compared to the respective control (PBS or DMSO). Data are expressed as mean of three independent measurements \pm s.d. p-values vs. control: $\mathrm{p}<0.05$ for $(\mathrm{A}, \mathrm{B}, \mathrm{D}$ and $\mathrm{E})$; $\mathrm{p}<0.03$ for $(\mathrm{C})$; $\mathrm{p}<0.01$ for $(\mathrm{F})$.

P2 $(0.831 \mu \mathrm{g} / \mathrm{mg})$ samples, respectively. On the other hand, G2 was the richest sample in lipophilic proteins $(0.545 \mu \mathrm{g} / \mathrm{mg})$ among all the RJs, while P3 $(0.207 \mu \mathrm{g} / \mathrm{mg})$ the poorest one.

Protein extracts were then subjected to one dimensional denaturing gel electrophoresis and Coomassie Blue staining (Fig. 2). No qualitative difference could be observed among the various samples. In general, the hydrophilic protein profile of all the RJs was characterized by 8 principal bands. According to literature data $(5,32)$ and thanks to a standard of molecular weights (MW), we were able to recognize each one of the protein spots. In particular, MRJP1, MRJP2, MRJP3, their isoforms and their fragments were identified (Fig. 2A). In the same manner, we also identified the three protein bands detected in the gel lanes where the lipophilic portions of the RJs were fractionated. They corresponded to MRJP5 and to its isoform and fragment (Fig. 2B).
Biological activity of the RJs on mammalian cells. The lipophilic and hydrophilic fractions of the RJs were purified as described in Materials and methods and used to treat, for 24 and $48 \mathrm{~h}$, three mammalian cell lines: C2C12, PC3 and SH-SY5Y. In particular, all the treatments were performed at three different concentrations, that is the equivalent of the hydrosoluble or liposoluble molecules contained in 250, 750 and $1250 \mu \mathrm{g}$ of RJ, respectively, per $\mathrm{ml}$ of culture medium. Cell growth was measured by MTT assay and the data are reported in Fig. 3A-F.

In $\mathrm{C} 2 \mathrm{C} 12$, the hydrophilic extracts of the RJs, except that $\mathrm{P} 1$, slightly induced an increase of cell proliferation after $24 \mathrm{~h}$ of incubation with the lowest dose (maximum value $+24.95 \%$ for G1). On the other hand, all the other treatments, at 24 and $48 \mathrm{~h}$ with the remaining concentrations, showed a weak reduction of cell growth, reaching the best antiproliferative effect $(-37.53 \%)$ using the $\mathrm{P} 2$ hydrophilic fraction at $1250 \mu \mathrm{g} / \mathrm{ml}$ for 
$48 \mathrm{~h}$. Singularly, G1 sample determined an increase of $\mathrm{C} 2 \mathrm{C} 12$ cells after $48 \mathrm{~h}$ of exposure to $750 \mu \mathrm{g} / \mathrm{ml}$ (Fig. 3A).

All lipophilic portions of the RJs caused a slight decrease of $\mathrm{C} 2 \mathrm{C} 12$ proliferation after $24 \mathrm{~h}$ of exposure with 250 and $750 \mu \mathrm{g}$ of extract per $\mathrm{ml}$ of culture medium (maximum value $-26.01 \%$ for P2 at $750 \mu \mathrm{g} / \mathrm{ml}$ ). The same treatments, after $48 \mathrm{~h}$, showed a rescue of the cell growth (maximum value $+36.51 \%$ for $\mathrm{G} 3$ at $750 \mu \mathrm{g} / \mathrm{ml}$ ), except the P3 sample. At the highest concentration, the RJ fractions did not exercise a significant variation of the cell reproduction at $24 \mathrm{~h}$, while, at $48 \mathrm{~h}, \mathrm{P} 1$, G2 and G3 samples induced hyperproliferative phenomena (maximum value $+36.51 \%$ for $\mathrm{G} 3$ ) (Fig. 3B).

PC 3 cells did not show any substantial modification of their cell growth after exposure, for $24 \mathrm{~h}$, to all doses of the hydrophilic fractions, except G3 $(+30.46 \%$ at $750 \mu \mathrm{g} / \mathrm{ml} ;+22.41 \%$ at $1250 \mu \mathrm{g} / \mathrm{ml})$. In contrast, after $48 \mathrm{~h}$, all treatments caused an increase of the cell count. In particular, G1 was the most proliferative extract, amounting to $+75.95 \%$ and $+114.14 \%$ at 750 and $1250 \mu \mathrm{g} / \mathrm{ml}$, respectively (Fig. 3C).

In PC 3 cells, all lipophilic extracts of the RJs did not induce significant changes in the proliferation rate. In general, results of all treatments at $250 \mu \mathrm{g} / \mathrm{ml}$, for $24 \mathrm{~h}$, at $750 \mu \mathrm{g} / \mathrm{ml}$, for 24 and $48 \mathrm{~h}$, and at $1250 \mu \mathrm{g} / \mathrm{ml}$, for $48 \mathrm{~h}$ were very similar to the control, expect that G1 (+14.20\%) and P2 (-17.41\%) at 750 and $1250 \mu \mathrm{g} / \mathrm{ml}$, in that order, after $48 \mathrm{~h}$. On the other hand, we observed that the lowest dose of treatment with all RJ fractions caused, after $48 \mathrm{~h}$, a weak antiproliferative effect (maximum value $-24.00 \%$ for $\mathrm{G} 3$ ), while the highest one determined, at $24 \mathrm{~h}$, a feeble pro-proliferative effect (maximum value +16.63 for G2) (Fig. 3D).

SH-SY5Y cells reduced their proliferation after exposure, for $24 \mathrm{~h}$, to the lowest dose of hydrophilic extracts (maximum value $-30.83 \%$ for P1). All the other treatments at $250 \mu \mathrm{g} / \mathrm{ml}$, for $48 \mathrm{~h}$, at $750 \mu \mathrm{g} / \mathrm{ml}$, for 24 and $48 \mathrm{~h}$, and at $1250 \mu \mathrm{g} / \mathrm{ml}$, for $24 \mathrm{~h}$, determined a variable decrease of the cell growth (maximum value $-26.83 \%$ for $\mathrm{P} 2$ at $1250 \mu \mathrm{g} / \mathrm{ml}$ ), except that $\mathrm{P} 2$ and $\mathrm{G} 2$ extracts in some cases. After $48 \mathrm{~h}$, the highest doses of P1, P2 and G1 samples did not produce any significant alteration compared to the control, while P3, G2 and G3 ones induced an increase of the cell proliferation of $+24.74 \%,+55.97 \%$ and $+41.72 \%$, respectively (Fig. 3E).

Surprisingly, all lipophilic fractions of the RJs caused a strong reduction of SH-SY5Y cell growth, in a dose- and timedependent manner. In particular, after treatment at $1250 \mu \mathrm{g} / \mathrm{ml}$ for $48 \mathrm{~h}$, the cell proliferation was reduced by RJ extracts in a range which varied between -65.62\% (P1 sample) and -79.53\% (P3 sample) (Fig. 3D).

Finally, to facilitate the comprehension of the biological effect exerted by all RJs on the mammalian cell lines and individuate the general trend of their treatments, the mean of the results previously obtained after exposure with the different RJ fractions, in each condition, was calculated (Fig. 4).

\section{Discussion}

We studied the biochemical composition of six different RJs, with the purpose of understanding if these matrixes were characterized by homogeneous and similar chemical profiles or by specific and typical spectra. To do it, a high-throughput GC-MS analysis was carried out both on methanol and on diethyl ether extracts of the RJs (Fig. 1), detecting a total of 348 and 276 different compounds, respectively (Table I). Literature data usually report a substantially lower number of molecules associated to $\mathrm{RJ}(11,26)$, indicating that the present research can be considered a very in-depth and original work which does not limit itself to the identification of the main chemical markers of the RJ but reveals all its components. In general, the amount of substances that were peculiar of only one sample (class 4 for each type of extraction, Table I) was always greater than those commonly detectable in two or more RJs (classes 3, 2 and 1), suggesting that these bee products are almost impossible to standardize. In fact, RJ composition is strongly dependent on several factors, such as environment conditions, genetics and physiology of the bee colony, plant biodiversity distributed around the hive (33).

The chromatographic study revealed that the acids, including free fatty acids, were the most abundant compounds in all RJs, as widely reported in literature $(34,35)$. In particular, 10-HDA and its saturated form, considered as authenticity and freshness markers of RJs (36), were detected in all matrixes, except in G2 and G3, suggesting that these molecules cannot be used as absolute parameters for RJ certification and/or that G2 and G3 samples were partially spoiled (deriving from large distribution network, see Materials and methods). In the RJs, we also detected high concentrations of plant phenolic derivatives (i.e. m-phenethyl-benzonitrile) and alcans (i.e. eicosane) with antimicrobial and antioxidant properties, in coherence with other works $(37,38)$. On the other hand, low doses of sugars and peptides could be revealed only in methanol extracts.

Another innovative aspect of the current work was the fractionation of the RJ proteins according to their lipophilicity. All RJs showed an higher content of hydrosoluble proteins than liposoluble ones (Table II). Thanks to one-dimensional SDS-PAGEs (Fig. 2), we were also able to separate and distinguish these proteins in all samples. In particular, MPRJ1 appeared as the most abundant of the hydrophilic proteins, followed by MPRJ2 and 3. On the contrary, MPRJ5 was the only one which could be found in the lipophilic protein extracts. Finally, MPRJ4 was not detectable in any fractions, as expected due to the low expression level of its mRNA in nurse bees (39). The multiple isoforms and fragments of the RJ proteins could be easily explained by the existence of several repeated regions into their amino acidic sequences and by degradation processes, respectively (32). In general, our results did not reveal qualitative differences in the protein profiles of the six samples, as happened in GC-MS analysis, possibly because the protein composition of the RJ is influenced by fewer factors than its chemical assortment.

Since only a few scientific works describe the antineoplastic properties of the RJ, we focused our research on in vitro analysis of the biological effect of RJs on cell growth of three different mammalian cell lines (C2C12, PC3 and SH-SY5Y). The choice of these specific cell models was encouraged by the lack of studies on RJ bioactivity on them. Moreover, for the first time in literature, the cell treatments were carried out using, separately, both hydrophilic and lipophilic fraction of the RJs, at various concentrations and times. With respect to the control, each fraction of RJ exercised a typical effect on the growth rate of the treated cells (Fig. 3). However, in most cases, we observed that extracts of different RJs surprisingly induced 


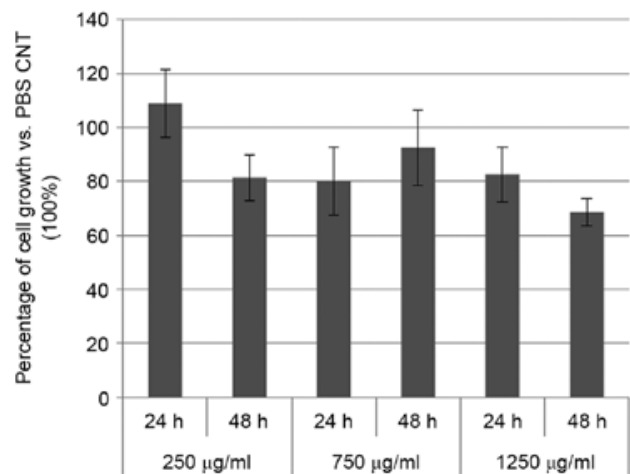

c

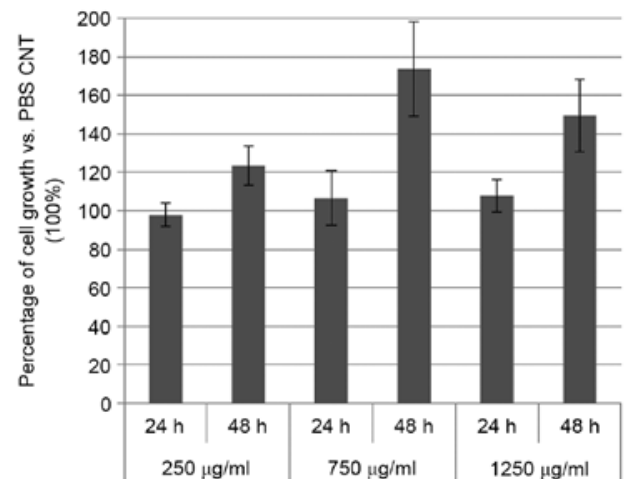

E

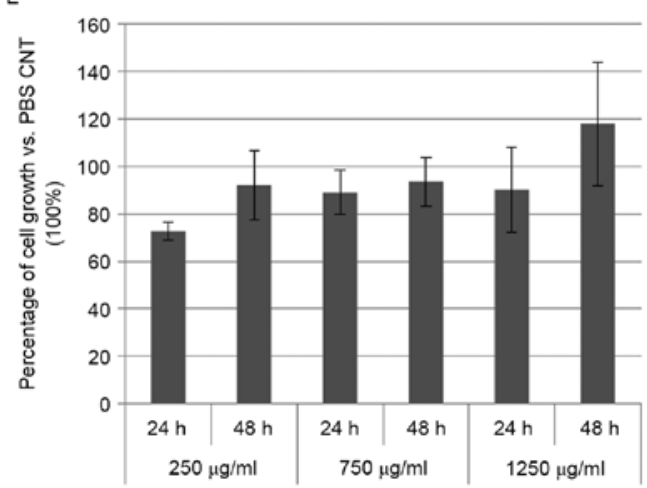

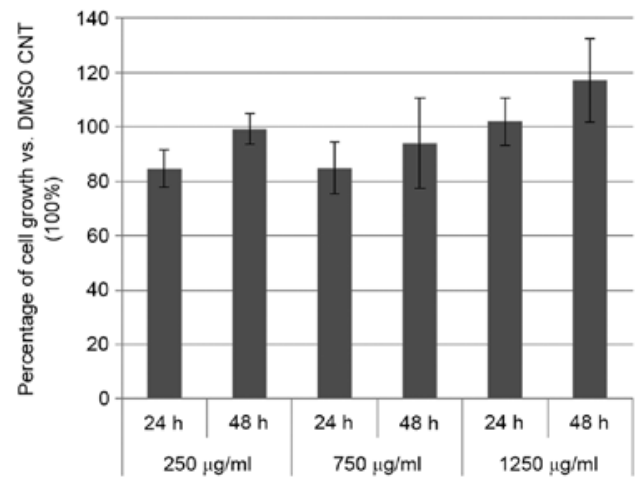

D

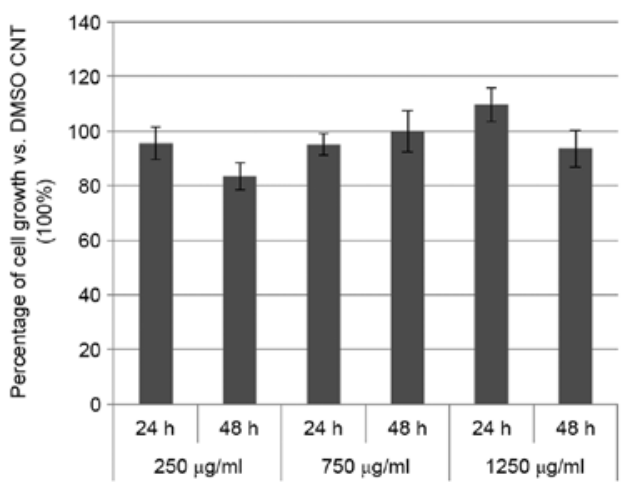

$\mathrm{F}$

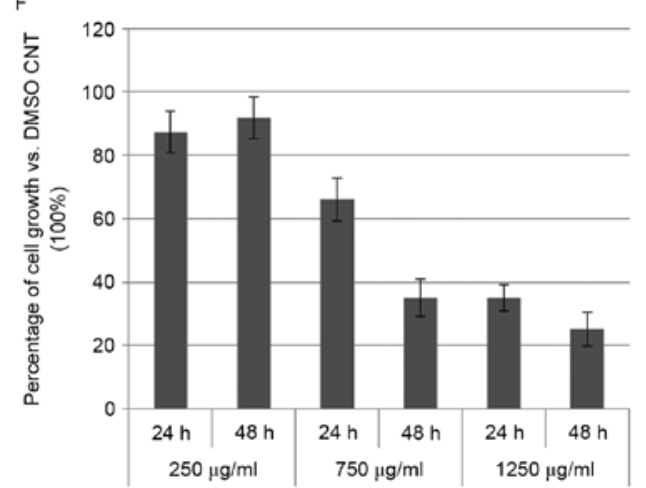

Figure 4. Resuming diagrams of the MTT results reported in Figure 3. Each graph represent the mean value \pm s.d. of the six biological effects induced by the hydrophilic (A, C and E) or lipophilic (B, D and F) extracts of the RJs (P1, P2, P3, G1, G2 and G3) on C2C12 (A and B), PC3 (C and D) and SH-SY5Y (E and F) cells, after treatment (for 24 and $48 \mathrm{~h}$ ) at different concentrations $(250,750$ and $1250 \mu \mathrm{g}$ per ml of culture medium). Results were reported as percentage of cell growth compared to the respective control (PBS or DMSO); $\mathrm{p}$-values vs. control: $\mathrm{p}<0.05$ for (A, B, D and E); $\mathrm{p}<0.02$ for (C); $<<0.01$ for (F).

a similar proliferative trend on the same cells; although each RJ had a peculiar biochemical profile (Table I) and protein content (Table II).

In general, the hydrophilic fraction of the RJs caused a small decrease of $\mathrm{C} 2 \mathrm{C} 12$ proliferation, while the respective lipophilic portion determined just a slight increase of the cell growth, both in a time- and dose-dependent manner (Fig. 4A and B). On PC3, the hydrophilic extracts caused a timedependent over-proliferation, while the lipophilic ones did not show any significant effect (Fig. 4C and D). Finally, the hydrophilic samples did not effectively influence SH-SY5Y growth rate, whereas antiproliferative effects were extraordinarily revealed by the lipophilic fractions, according to concentration and exposure of the treatments (Fig. 4E and F). This last outcome could suggest a potential medical application of the lipophilic portion of the RJ as antineoplastic treatment for human neuroblastoma.

Similar results were already described in Tamura et al (25), where the authors reported that lipid components of the RJ presented antineoplastic property against slow-growing cancers (i.e. P388 and L1210 murine lymphocytic leukemias, 180 murine sarcoma), such as SH-SY5Y neuroblastoma we studied. Obviously, other in vitro and in vivo studies should be carried out to confirm this hypothesis. Finally, the use of RJ to prevent the onset and slow down the growth of the neuroblastoma could also be supported by the evidence, documented in Hashimoto et al (40) and Hattori et al (41), which proved that RJ fatty acids (in particular 10-HAD) showed neurotrophic and differentiative activity on murine neuronal cells. 
It is quite difficult to establish which RJ compound exerts antiproliferative effects, since RJs usually possess very different compositions, as demonstrated in the present study. However, we hypothesize that this specific bioactivity is strongly linked to lipophilic molecules, such as those detected in all our samples (eicosane; dodecane, 2,6,11-trimethyl; octacosyl trifluoroacetate; phenantrenemetil-2 phenilcinnamato; class 1, Table I). The predominant biological role that literature assigned to 10-HAD (and its saturated form) in the RJ was unexpectedly not confirmed in the current research. In fact, all RJs induced SH-SY5Y growth inhibition, although some of them were lacking this fatty acid. Previous evidence let us to believe that all RJ compounds work in synergy to reach the final observed effect.

In conclusion, all lipophilic fractions extracted from chemically different RJs surprisingly shared a common antitumoral feature against human neuroblastoma.

\section{Acknowledgements}

The present study was supported and financed by Regione Lazio (FILAS-RU-2014-1122) through the SMART CAMPUS PROGRAM 'Analisi qualità delle materie prime, origine e verifica di contaminazione di alimenti vegetali' - codice F1-2016-0069 (CUP: E82I15000980002).

\section{References}

1. Haydak MH: Honey bee nutrition. Annu Rev Entomol 15: 143-156, 1970.

2. Contessi A: Le api biologia, allevamento, prodotti. 4th edition. Edagricole, Bologna, 2016 (In Italian)

3. Nagai T and Inoue R: Preparation and functional properties of water and alkaline extract of royal jelly. Food Chem 84: 181-186, 2004.

4. Hanes J and Simúth J: Identification and partial characterization of major royal jelly protein of honeybee (Apis mellifera). $\mathbf{J}$ Apic Res 31: 22-26, 1992.

5. Schmitzová J, Klaudiny J, Albert S, Schröder W, Schreckengost W, Hanes J, Júdová J and Simúth J: A family of major royal jelly proteins of the honeybee Apis mellifera L. Cell Mol Life Sci 54 1020-1030, 1998.

6. Boselli E, Caboni MF, Sabatini AG, Marcazzan GL and Lercker G: Determination and changes of free amino acids in royal jelly during storage. Apidologie (Celle) 34: 129-137, 2003.

7. Fujita T, Kozuka-Hata H, Ao-Kondo H, Kunieda T, Oyama M and Kubo T: Proteomic analysis of the royal jelly and characterization of the functions of its derivation glands in the honeybee. J Proteome Res 12: 404-411, 2013.

8. Lercker G, Savioli S, Vecchi MA, Sabatini AG, Nanetti A and Piana L: Carbohydrate determination of royal jelly by high resolution gas chromatography (HRGC). Food Chem 19: 255-264, 1986.

9. Lercker G, Capella P, Conte LS, Ruini F and Giordani G: Components of royal jelly: I. Identification of the organic acids. Lipids 16: 912-919, 1981.

10. Caboni MF, Sabatini AG and Lercker G: La gelatina reale: origine, proprietà e composizione / Royal jelly:origin, properties and composition. APOidea 1: 72-79, 2004.

11. Melliou E and Chinou I: Chemistry and bioactivity of royal jelly from Greece. J Agric Food Chem 53: 8987-8992, 2005.

12. Gómez-Caravaca AM, Gómez-Romero M, Arráez-Román D, Segura-Carretero A and Fernández-Gutiérrez A: Advances in the analysis of phenolic compounds in products derived from bees. J Pharm Biomed Anal 41: 1220-1234, 2006.

13. Mohamed AA, Galal AA and Elewa YH: Comparative protective effects of royal jelly and cod liver oil against neurotoxic impact of tartrazine on male rat pups brain. Acta Histochem 117: 649-658, 2015 .
14. Viuda-Martos M, Ruiz-Navajas Y, Fernández-López J and Pérez-Alvarez JA: Functional properties of honey, propolis, and royal jelly. J Food Sci 73: R117-R124, 2008.

15. Guo H, Saiga A, Sato M, Miyazawa I, Shibata M, Takahata Y and Morimatsu F: Royal jelly supplementation improves lipoprotein metabolism in humans. J Nutr Sci Vitaminol (Tokyo) 53: 345-348, 2007.

16. Münstedt K, Bargello M and Hauenschild A: Royal jelly reduces the serum glucose levels in healthy subjects. J Med Food 12: 1170-1172, 2009.

17. Cihangir E, Orhan D, Ercument O and Yasam B: The effects of royal jelly on autoimmunity in Grave's disease. Endocrinologia 30: 175-183, 2006.

18. Majtán J, Kovácová E, Bíliková K and Simúth J: The immunostimulatory effect of the recombinant apalbumin 1-major honeybee royal jelly protein-on $\mathrm{TNFalpha}$ release. Int Immunopharmacol 6: 269-278, 2006.

19. Bincoletto C, Eberlin S, Figueiredo CA, Luengo MB and Queiroz ML: Effects produced by Royal Jelly on haematopoiesis: Relation with host resistance against Ehrlich ascites tumour challenge. Int Immunopharmacol 5: 679-688, 2005.

20. Hidaka S, Okamoto Y, Uchiyama S, Nakatsuma A, Hashimoto K, Ohnishi ST and Yamaguchi M: Royal jelly prevents osteoporosis in rats: Beneficial effects in ovariectomy model and in bone tissue culture model. Evid Based Complement Alternat Med 3: 339-348, 2006.

21. Yatsunami $\mathrm{K}$ and Echigo T: Antibacterial action of royal jelly. Bull Fac Agric Tamagawa Univ 25: 13-22, 1985.

22. Fujiwara S, Imai J, Fujiwara M, Yaeshima T, Kawashima T and Kobayashi K: A potent antibacterial protein in royal jelly. Purification and determination of the primary structure of royalisin. J Biol Chem 265: 11333-11337, 1990.

23. Taniguchi Y, Kohno K, Inoue S, Koya-Miyata S, Okamoto I, Arai N, Iwaki K, Ikeda M and Kurimoto M: Oral administration of royal jelly inhibits the development of atopic dermatitislike skin lesions in NC/Nga mice. Int Immunopharmacol 3: 1313-1324, 2003.

24. Shirzad M, Kordyazdi R, Shahinfard N and Nikokar M: Does Royal jelly affect tumor cells. J HerbMed Pharmacol 2: 45-48, 2013.

25. Tamura T, Fujii A and Kuboyama N: Antitumor effects of royal jelly (RJ). Nippon Yakurigaku Zasshi 89: 73-80, 1987 (In Japanese).

26. Isidorov VA, Bakier S and Grzech I: Gas chromatographicmass spectrometric investigation of volatile and extractable compounds of crude royal jelly. J Chromatogr B Analyt Technol Biomed Life Sci 885-886: 109-116, 2012.

27. Gismondi A, Canuti L, Grispo M and Canini A: Biochemical composition and antioxidant properties of Lavandula angustifolia Miller essential oil are shielded by propolis against UV radiations. Photochem Photobiol 90: 702-708, 2014.

28. Giovannini D, Gismondi A, Basso A, Canuti L, Braglia R, Canini A,Mariani F and Cappelli G: Lavandula angustifolia Mill. essential oil exerts antibacterial and anti-inflammatory effect in macrophage mediated immune response to Staphylococcus aureus. Immunol Invest 45: 11-28, 2016.

29. Li J, Wang T, Zhang Z and Pan Y: Proteomic analysis of royal jelly from three strains of western honeybees (Apis mellifera). $\mathrm{J}$ Agric Food Chem 55: 8411-8422, 2007.

30. Bradford MM: A rapid and sensitive method for the quantitation of microgram quantities of protein utilizing the principle of protein-dye binding. Anal Biochem 72: 248-254, 1976.

31. Gismondi A, Lentini A, Tabolacci C, Provenzano B and Beninati S: Transglutaminase-dependent antiproliferative and differentiative properties of nimesulide on B16-F10 mouse melanoma cells. Amino Acids 38: 257-262, 2010.

32. Scarselli R, Donadio E, Giuffrida MG, Fortunato D, Conti A, Balestreri E, Felicioli R, Pinzauti M, Sabatini AG and Felicioli A: Towards royal jelly proteome. Proteomics 5: 769-776, 2005.

33. Howe SR, Dimick PS and Benton AW: Composition of freshly harvested and commercial royal jelly. J Apic Res 24: 52-61, 1985.

34. Kodai T, Umebayashi K, Nakatani T, Ishiyama K and Noda N: Compositions of royal jelly II. Organic acid glycosides and sterols of the royal jelly of honeybees (Apis mellifera). Chem Pharm Bull (Tokyo) 55: 1528-1531, 2007.

35. Bogdanov S: Royal Jelly, Bee Brood: Composition, Health, Medicine: A Review. Bee Product Sci 1-36, 2011 
36. Antinelli JF, Zeggane S, Dav Ico R, Rognone C, Faucon JP and Lizzani L: Evaluation of (E)-10-hydroxydec-2-enoic acid as a freshness parameter for royal jelly. Food Chem 80: 85-89, 2003.

37. Matsuka M: Content of benzoic acid in royal jelly and propolis. Mitsubachi Kagaku 14: 79-80, 1993

38. Rizwan K, Zubair M, Rasool N, Riaz M, Zia-Ul-Haq M and de Feo V: Phytochemical and biological studies of Agave attenuata. Int J Mol Sci 13: 6440-6451, 2012

39. Klaudiny J,Hanes J,Kulifajová J,Albert Š and Šimúth J: Molecular cloning of two cDNAs from the head of the nurse honeybee (Apis mellifera L.) for coding related proteins of royal jelly. J Apic Res 33: 105-111, 1994. doi: 10.1080/00218839.1994.11100857.
40. Hashimoto M, Kanda M, Ikeno K, Hayashi Y, Nakamura T, Ogawa Y, Fukumitsu H, Nomoto H and Furukawa S: Oral administration of royal jelly facilitates mRNA expression of glial cell line-derived neurotrophic factor and neurofilament $\mathrm{H}$ in the hippocampus of the adult mouse brain. Biosci Biotechnol Biochem 69: 800-805, 2005.

41. Hattori N, Nomoto H, Fukumitsu H, Mishima S and Furukawa S: Royal jelly and its unique fatty acid, 10-hydroxy-trans-2decenoic acid, promote neurogenesis by neural stem/progenitor cells in vitro. Biomed Res 28: 261-266, 2007. 